\title{
DERECHO PROCESAL
}

\section{La prueba en el Derecho Procesal Norteamericano}

Por el Dr. MANuel R. GARCia-MORA (")

El Derecho de Pruebas, o como se le llama en el Derecho Anglo Americano, el Derecho de Evidencia (Law of Evidence) es el sistema de reglas $Y$ de principios que regula la admisibilidad de las pruebas en el proceso de un juicio civil o criminal. Puede decirse que, después del Derecho Constitucional, el Derecho de Pruebas es la rama más importante del Derecho, pues como Bentham dijo hace algún tiempo: "El Derecho de Pruebas es la base de la justicia". Antes de entrar en un análisis de las reglas que se aplican: en la admisibilidad de la prueba, es necesario aclarar ciertos conceptos que ayudarán al 'mejor entendimiento de la prueba en el Derecho Nortoamericano.

\section{Observaciones Generales}

Ante todo debe afirmarse que el Derecho de Pruebas no es una ciencia pura de lógica; tampoco es un cuerpo de reglas para valorizar las pruebas; es, $\sin$ embargo, un sistema de reglas que regula la admisibilidad de la prueba. Es, pues, un sistema de admisibilidad y como tal sólo opera en la etapa del juicio mismo, esto es, en el período comprendido por la audiencia pública. Naturalmente, antes de la audiencia los abogados de las partes han recogido las pruebas que más tarde ofrecerón. El Derecho de Pruebas no trata de ese proceso preliminar; sólo regula la admisibilidad de dichas pruebas cuando se presentan ante la Corte en el curso de la audiencia.

(*) Catedrático de la Facultad de Derecho de la Universidad de Michigan (EE: UU.) y enviado en Misión de la Comisión Fulbright al Perí (1959). - Graduado en Derecho $y$ Ciencias Políticas en la Universidad de Harvard, $Y$ Doctorado en Derecho en la Universidad de Yale. Autor de numerosos artículos sobre Derecho Internacional y Derecho Comparado publicados en Revistas de Derecho de los Estados Unidos. Autor del libro titulado International Law and Asylum as a Human Fight (Washington, D.C.: Public Affairs Press, 1956); del artículo sobre el Derecho de Asilo publicado en la Encyclopae. dia Britannica, $Y$ de la Defensa Política del Hemisferio Occidental publicado en la Encylopedia Americana. 
Debe notarse que este período comprende la etapa que comienza con la audiencia $y$ termina cuando el jurado se retira $\alpha$ deliberar.

Siendo un sistema de admisibilidad, la función del Juez entra inmediatamente en operación, pues es precisamente el Juez quien determina la admisibilidad de una prueba. Aquí vemos la división entre las funciones del Juez y las funciones del Jurado: el Juez determina la admisibilidad de la prueba, lo que es una determinación de derecho, mientras que el Jurado valoriza las pruebas alcanzando así un veredicto determinado.

Como se ha vislumbrado en el párrafo anterior, el sistema del jurado prevalece en los Estados Unidos tanto para casos criminales como para casos civiles. El derecho a ser juzgado por un jurado es un derecho constitucional de las partes, el que se encuentra garantizado en las Enmiendas Sexta y Séptima de la Constitución Nacional y en las diversas constituciones de los Estados. Debe verse, por consiguiente, que cuando las partes introducen las priebas tienen pleno conocimiento del efecto que estas pruebas tendrán ante el jurado, $y$ es por ello que sus alegatos se dirigen a los miembros del jurado.

Es también de suma importancia recalcar que el sistema AngloAmericano de litigio es un sistema adversario en contraposición al sistema inquisitivo de los países de Derecho Romano. De acuerdo con el sistema adversario el juicio se desenvuelve exclusivamente del material que las partes mismas presentan. En este sistema la función del Juez se limita a pasar sobre la admisibilidad de las pruebas, pero al desempeñar esta función el Juez no invoca las reglas pertinentes, lo que significa que las reglas del Derecho de Pruebas no operan automáticamente. Las partes mismas tienen la obligación de invocar las reglas del caso e informar al Juez oportunamente de sus objeciones. La responsabilidad entera descansa en las partes mismas.

Finalmente, delineando el Derecho de Pruebas existen tres derechos fundamentales de las partes. Estos derechos son: 1) las partes deben ser informadas de todas las pruebas que se presentan contra ellas, esto es, no existen pruebas secretas; 2) las partes tienen el derecho de tener la oportunidad justa y amplia de rebatir estas pruebas y de exponer sus debilidades; $y$ 3) las partes tienen el derecho de preguntar y de repreguntar a los testigos que se usan contra ellas. Pero estos derechos tienen un significado más profundo, pues hacen del Derecho de Pruebas uno de los medios de hacer efectivos los derechos constitucionales de las personas. De allí que el Derecho de Pruebas debe entenderse como un sistema de procedimientos básicos que protege los derechos constitucionales de las partes.

\section{Información o "Noticia" Judicial}

El objeto mismo del Derecho de Pruebas es el hecho y acto jurídico controvertidos. Sin embargo, en el curso de un juicio se presentan situaciones de hecho $o$ de derecho que no necesitan comprobación simplemente porque son de tanta notoriedad y evidencia que caen bajo el conocimiento 
general de las personas de una comunidad (1). En relación con estos hechos notorios y evidentes el Juez debe tomar, como decimos, "noticia" o información judicial (Judicial Notice), de manera que la parte que se base en estos hechos está exonerada de presentar pruebas. Algunas veces, aunque estos hechos no aparecen con suficiente evidencia a primera vista, su veracidad puede muy bien comprobarse consultando fuentes de autoridad indiscutible (2).

En el ordenamiento jurídico Norteamericano, por lo general se exige la prueba del derechn extranjero, lo que se exigió en el Derecho Común clásico. Sin embargo, como excepción a esta regla general, en el derecho de los Estados de Massachusetts, Mississippi, North Carolina y West Virginia hay estatutos especiales que han suprimido la prueba del derecho extranjero: $y$ el derecho de los Estados de Michigan y New York permite que el Juez a discreción tome "noticia" judicial del derecho extranjero. El Estado de Maryland permite que sus cortes tomen noticia judicial del derecho extranjero cuando el derecho del país en cuestión se basa en el Derecho Común inglés.

Por supuesto, la ley nacional y la Constitución Nacional no necesitan pruebcrs, ya que la misma Constitución establece su supremacía. En lo que se refiere a la ley de los otros Estados de la Unión las cortes han establecido la presunción que la ley de un Estado es la misma que la ley del Estado donde el juicio se ventila. Esta presunción tiene bases lógicas, ya que tados los Estados, salvo Lousiana, se basan en el sistema de Derecho Común. Esta presunción, sin embargo, no se aplica al Estado de Louisiana precisamente porque su derecho se remonta al derecho francés, de manera que en relación a este Estado su ley necesita comprobación.

Hechos científicos que sean evidentes y notorios en la comunidad científica son también susceptibles de noticia o conocimiento judicial. Asś, como no hay controversia entre los científicos que un examen de la sangre de los padres presuntos puede negar la paternidad de un niño, el Juez puede conocer judicialmente la no existencia de la paternidad (5). El único recurso que tiene la parte perjudicada por tal examen es probar que el examen no se condujo de acuerdo con los métodos apropiados para asegurar exactitud. Una vez que se ha probado exactitud y competencia en la conducta del examen, el Juez no puede ignorar el resultado como tampoco el Jurado. Estos exámenes, sin embargo; no se pueden usar para probar la paternidad, pues los científicos están de acuerdo en que la paternidad no se puede estrblecer

1. Uniform Rules of Evidence, Regla 9.

2. Por ejemplo, si en al curso do un juicio se necesita deteminar el día en que cayó el 23 de Juilo de 1956, aunque este ciato no se conczca a primera visic se puede verificar simplemante consultando un calendario del cño en cuestión.

3. Charles T. McCormick, Handbook of the Lav of Evidence, p. 698 (St. Paul: West Publishing Co., 1954).

4. Constitución Nacional, Artículo VI.

5. Jordan v. Mace, 144 Me. 351, 69 A. 2d 670 (1949); este caso debe compararse con Bery v. Chaplin, 74 Cal. App. 2d 652, 168 P. đ 442 (1946), donde el Juez instruyó al Jurado que podía pasar por alto el examen de sangre que negaba la paternidad. 
a base de ellos. Sólo pueden probar que tal o cual persona no es el padre de tal o cual niño.

Es claro que si una de las partes impugna la autenticidad de la cuestión que se alega que es evidente y notoria, esa parte puede presentar pruebas contrarias, en cuyo caso el hecho pasa a la categoría de un hecho controvertido para cuyo establecimiento las pruebas deben presentarse y ser reguladas de acuerdo con las reglas pertinentes.

\section{Medios de Prueba}

Nuestro Derecho de Pruebas autoriza tres clases de pruebas que se pueden utilizar para probar hechos controvertidos. Son: la prueba demostrativa, también llamada prueba real (real proof); prueba testimonial (testimonial proof), y prueba circunstancial (circunstancial proof).

La prueba demostrativa o real consiste en traer la cosa misma o su reproducción en corte para su inspección ocular por el jurado. Tales instrumentos como el arma que se usó para cometer el crimen, la ropa manchada de sangre del acusado, fotografías de la víctima, radiografías, etc., caen bajo la categoría de pruebas demostrativas. La misma naturaleza de estas pruebas lleva consigo el riesgo que inflamen la pasión y la simpatía del jurado; de allí que el Juez tenga que ejercer discreción en su admisión. El Juez debe balancear el efecto probatorio de estas pruebas con el efecto perjudicial que puedan tener. Si la cuestión es susceptible de testimonio oral de un testigo, no hay duda entonces que la demostración de la prueba ante el jurado tendrá un efecto acumulativo, en cuyo caso el Juez debe negar su admisión. En cualquier caso, antes de pasar sobre la admisibilidad de estas pruebas el Juez tiene que cerciorarse que tal o cual arma fué en realidad la que se usó para cometer el crimen, o que el vestido cubierto de sangre pertenece al acusado. Esto es lo que se conoce con el nombre de la autenticación de la prueba, lo que puede hacerse por medio del testimonio de testigos, por confesión voluntaria del acusado o por prueba circunstancial. Como se ve, la prueba demostrativa no es prueba directa, $y$ cuando es circunstancial el riesgo de que sea perjudicial aumenta grandemente.

La prueba testimonial es quizás el medio de prueba que contribuye más poderosamente al descubrimiento de la verdad. Las reglas que regulan la admisibilidad de esta prueba son reglas de exclusión, esto es, se usan para excluír testimonio. Los pasos que se siguen en la admisbilidad de la prueba testimonial son tres: 1) la determinación de la competencia del testigo; 2) el examen principal y la repregunta del testigo; $\mathrm{y}$, 3) la im. pugnación del testigo.

En cuanto a la competencia del testigo, este requisito se refiere a su competencia para dar testimonio, y una objeción a la competencia es

5. E.M. Morgan, J.M. Maguire y J.B. Weinstein, Cases and Materials on Evidence p. 81 Brooklyn: The Foundation Press, 4th ed., 1957). 
necesario dirigirla al testigo mismo y no a lo que el testigo ha dicho o va $a$ decir. Las causales que dan lugar a la incompetencia son por lo general establecidas por legislación, pero usualmente se aceptan como tales la edad, mentalidad del testigo, creencias religiosas, el interés que el testigo tenga en el resultado del litigio, $y$ un fallo de culpabilidad anterior (7). Debe añadirse por el Juez antes de que el testigo rinda su testimonio. El interés como causal para tachar a un testigo se ha abolido en casi todos los Estados, aunque todavía existe un aspecto de esta causal que impide a un testigo dar testimonio sobre transacciones que ha tenido con una persona ya muerta. Esta regla se conoce con el nombre de "la regla del hombre muerto" (Dead Man Rule), y se basa en el temor de que una persona mienta para proteger sus intereses, cuando se trata de transacciones que ha tenido con otra persona ya muerta. En lo que se refiere a creencias religiosas, su significado consiste en que, como el testimonio debe darse bajo juramento, una persona que no crea en Dios no podrá prestar juramento. La mayoría de los Estados, sin embargo, ha promulgado leyes permitiendo que el juramento se preste $a$ base de cualquier persona a quien el testigo tenga en reverencia especial. Lo importante es que el testigo tenga conocimiento de los efectos que resultarán si no dice la verdad. Es significativo añadir, que bajo esta interpretación, niños pueden dar testimonio si tienen suficiente conocimiento de las implicaciones que lleva el decir la verdad (8). El mismo criterio se ha aplicado en algunos Estados a personas de mente insana, $Y$ en este sentido el Estado de Michigan se adhiere al principio que la locura afecta la credibilidad del testimonio y no su admisibilidad (9).

El examen y la repregunta de los testigos es quizás la etapa más importante del proceso, porque es aquí que el derecho de una persona de confrontar a sus acusadores se pondrá en práctica. Como ya hemos vislumbrado, hay dos 'exámenes que llevan el nombre de examen principal (examination in chief) y la repregunta (cross.examination). La parte que propone al testigo lo examina primero, pero este examen principal está estrictamente regulado. Una objeción común del adversario en esta etapa del examen es que las preguntas no son pertinentes. Una pregunta es pertinente cuando versa sobre cuestiones que están envueltas en el proceso. El interrogante principal tampoco puede preguntar lo que se llaman "leading questions", esto es, preguntas que sugieren 0 insinúan la respuesta. Tampoco pueden hacerse "misleading questions", que son preguntas que tienden $\alpha$ entrampar al testigo. Un tipo común de estas preguntas es, ¿cuándo ha dejado de pegarle a su esposa?, asumiendo que el testigo le pegaba a su esposa. Como se ve, este tipo de preguntas asume la veracidad del hecho controvertido,

7. La tacha de testigos por un fallo de culpabilidad anterior se ha abolido por estatuto en la mayoría de los Estados. Este movimiento hacia la abolición comenzó con el caso Rosen v. United States, 245 U.S. (1917), que cambió el Derecho Federal al respecto.

8. Hill v. Skinner, $81 \mathrm{Oh}$. App. 375, N.E. 2d 787 (1947). En este caso a un niño de cuatro años de edad la Corte lo declaró competente.

9. People v. Tomeczak, 250 Mich. 679 (1930), donde la Corte declaró la competencia para dar testimonio de dos muchachas menores de edad que se habían considerado imbéciles $Y$ que al dar el testimonio se encontraban en un asilo. 
Y aún cuando la parte adversa no ha objetado, el Juez tiene el deber de excluír preguntas de esta naturaleza, ya que su injusticia es evidente y no ayudan de ninguna manera al descubrimiento de la verdad. Debe añadirse que el testigo sólo da testimonio sobre hechos, lo que significa que no puedo dar su opinión acerca de los hechos. La opinión como testimonio se excluye porque el testigo está asumiendo el papel que pertenece al jurado, y aún en caso de testigos expertos, las preguntas hay que formularlas en forma hipotética. Una pregunta hipotética sería la siguiente: asumiendo la veracidad de lo que ha oído, y asumiendo que esta condición existía, ies su opinión que tal o cual resultado ocurrirá? Se ve qué esta pregunta se basa en una hipótesis, y el jurado todavía puede determinar la veracidad de los hechos que para propósitos de la pregunta se han considerado como verdaderos.

Una vez que el examen principal ha terminado, la parte adversa puede repreguntar al testigo. En la repregunta se permite formular preguntas que sugieren la respuesta, simplemente porque como el testigo ya ha dado su testimonio, el repreguntador no quiere escuchar la misma historia. El interrogante entonces tiene más latitud para elucidar los hechos. Sin embargo, en la repregunta surge el problema de la latitud que el interrogante tiene, $y$ en este sentido existen tres reglas que se aplican en los diferentes Estados. La primera regla se conoce como el nombre de la "regla Americona". y prevalece en la mayoría de los Estados como también en el ramo federal. De acuerdo con esta regla, el repreguntador está limitado a preguntar sobre cuestiones que se han preguntado en el examen principal del testigo. La segunda regla es la llamada "regla cmpliamente abierta" o "regla Inglesa" que estipula que el repreguntador puede preguntar sobre cualquier materia, aunque no se haya tocado en el examen principal del testigo. Finalmente, la regla llamada "regla de Michigan", de acuerdo con la cual el repreguntador puede preguntar sobre inferencias que se desprenden del examen principal del testigo. Ahora bien, si nueva materia se ha elucidado en la repregunta, el interrogante principal puede llamar al testigo y preguntar solamente esas materias nuevas.

El tercer paso en la prueba testimonial es la impugnación del testigo por medio de la cual se pone en tela de juicio el testimonio ya dado. Aquí el interrogante cuenta con bastante latitud, pues puede impugnar la veracidad de un testigo a base de prejuicio, interés, corrupción, fallo de culpabilidad anterior, otros actos ilícitos, testimonio contradictorio dado anteriormente y reputación de veracidad. Todos estos fcctores, sin embargo, deben ser pertinentes, de lo contrario serán excluádos. Lo remoto de estas condiciones también juega un papel importante, pues si un fallo de culpabilidad es tan remoto en el tiempo que no contribuirá a elucidar la verdad sino más bien $\alpha$ perjudicar injustamente al testigo, el Juez debe excluírlo como causal de impugnación. Además, la parte que propuso al testigo no puede impugnarlo, al menos que el testimonio de ese testigo coja el interrogante de sorpresa volviéndose así un testigo hostil. Otros Estados permiten entonces que el interrogante cambie su técnica de interrogante principal a repreguntado, para entonces poder hacer preguntas que sugieren la respuesta. El Derecho 
Federal es quizás el único que permite que una parte impugne a su propio testigo (10). Naturalmente, el jurado es el único que sabe si el testigo ha sido impugnado, y la función del Juez se reduce a mantener el examen dentro de las reglas e impedir que el interrogante haga del testigo una víctima de sus preguntas.

El tercer medio de prueba que el Derecho Anglo-Americano autoriza es la prueba circunstancial, que consiste en demostrar que si tal o cual condición existió, es probable que este otro resultado haya ocurrido. Por ejemplo, si un hombre escribe una carta amorosa a una mujer casada, y más tarde se encuentra a su esposo muerto por homicidio, la inferencia inmediatamente surge que la persona que escribió la carta tiene cierta conección. con el crimen. Pero la prueba circunstancial es prueba indirecta; de allí que su admisibilidad esté estrictamente regulada. En el caso dado, la inferencia que el hombre que escribió la carta tenga algo que ver con el crimen sólo se admitirá si esta inferencia es más probable que cualquier ot'a inferencia posible. Si existen inferencias igualmente posibles, la prueba circunsiancial en cuestión pierde todo efecto probatorio y sólo contribuirá a confundir la mente del jurado. Por consiguiente, su inadmisibilidad no está en duda.

Generalmente, como prueba defensiva el acusado puede llamar "testigos de carácter". El carácter de una persona es prueba circunstancial. Sin embargo, el carácter no es un hecho controvertido en el juicio, pero se vuelve tal si el acusado presenta testimonio de su buen carácter. Es una regla inflexible y altamente justa que el Fiscal no puede atacar el carácter del acusado al menos que el acusado haya puesto su carácter en el juicio. El acusado pone su carácter en el juicio llamando testigos que darán testimonio de la reputación del acusado. El testimonio de los testigos de carácter está limitado a la reputación que el acusado tiene en la comunidad; no pueden dar su opinión sobre tal reputación, como tampoco mencionar actos específicos del acusado. De cualquier manera, cuando el acusado ha presentado su carácter en el juicio, él "ha abierto la puerta" para que el Fiscal impugne ese carácter por medio de testigos o la repregunta de los testigos de carácter, salvo que el Fiscal está limitado a los hechos y las preguntas que se han hecho en el exómen principal de los testigos de carácter.

El hábito y la costumbre de una persona caen también bajo la categoria de prueba circunstancial. Por ejemplo, si la víctima en un accidente automovilístico tenía la costumbre de acelerar su automóvil precisamente en el lugar del accidente, esto costumbre de acelerar su coche será pertinente. Sin embargo, el hábito como prueba requiere que sea practicado con regularidad, y algunas cortes requieren que sea practicado con "regularidad invariable". Este requisito está basado en la lógica, pues si hay excepciones a la práctica, surgen inmediatamente probabilidades que no se practicó en el momento determinado.

10. Esto se permite de acuerdo con la Regla 43 (b) de las Reglas Federales de Proce-dimiento Civil. 


\section{La Regla del "Hearsay"}

Existe un tipo de Prueba en el Derecho Anglo-Americano que es inadmisible y que por consiguiente, el Juez no debe ni puede aceptarla. Es el llamado hearsay (oír decir) y ocupa un lugar extenso en el Derecho de Pruebas. El Dr. Wigmore, eminente tratadista norteamericano sobre el Derecho de Pruebas, opina que la regla que no permite la admisión de hearsay es quizás la contribución más importante del sistema Anglo-Āmericano a los métodos de procedimientos del mundo (11). "Hearsay" se puede definir como una declaración o escrito hecho por una persona y repetido en la corte por un testigo para probar la veracidad de lo que la declaración contiene. Por ejemplo, un testigo dá testimonio de que él oyó a $\bar{A}$ decir a $B$ que $A$ hizo tal o cual cosa. Este testimonio no es admisible por las razones siguientes: 1) cuando $\bar{A}$ hizo la declaración lo hizo sin la solemnidad del juramento que se acostumbra en las cortes. La declaración de $A$ fue hecha fuera de la corte y no bajo juramento. 2) No existe oportunidad de examinar y repreguntar a $A$, ya que no está presente en la Corte 3l. El testigo que repite la declaración de $A$ lo puede hacer incorrectamente.

De allí las razones por las cuales declaraciones de "hearsay" no son admisibles. Debe notarse que la declaración se usa para probar la veracidad de lo que contiene. Usando otra vez el ejemplo anterior, si el testigo da testimonio que él oyó a $\bar{A}$ decir a $B$ que $C$ era un ladrón, esta declaración será hearsay si la usamos para probar que $\mathrm{C}$ es un ladrón.

La doctrina conoce diferentes clases de hearsay. Se puede hablar de hearsay simple cuando el testigo dice que oyó a $\bar{A}$ decir a $B$ que él hizo esto o lo otro. También se habla de hearsay doble, cuando el testigo dice que $A$ le dijo que $B$ le dijo a C que había hecho esto. Finalmente, si la cadena de declaraciones es aún más larga tenemos un caso de hearsay múltiple, cuando el testigo da testimonio que él oyó a $A$ decir que $B$ había dicho que $C$ había declarado $a \mathrm{D}$ que este hecho sucedió.

Los ejemplos anteriores demuestran claramente la razón por la cual declaraciones de "hearsay" no son admisibles. Es necesario que la declaración se use para probar la veracidad de su contenido, y que el declarante original no esté disponible debido a que estó muerto o que una búsqueda no haya permitido encontrarlo. Es posible, sin embargo, que tales declaraciones tengan un valor probatorio $y$, por consiguiente, las cortes han ideado ciertas excepciones que permiten la admisión de la declaración cuando no se usa para probar la veracidad de su contenido, y aún cuando el declarante no esté disponible. Estas excepciones se basan en los siguientes factores: 1) el declarante ya no está disponible; 2) el testigo que oyó la declaración tiene conocimiento personal de la misma; y 3) este testigo está presente

11. John Wigmore, A Treatise on the Law of Evidence, Vol. 5, p. 27 (3d ed., 1940).

12. E.M. Morgan, "Hearsay Dangers and the Application of the Hearsay Concept", Harvard Law Review, Vol. 62, p. 177, (1948). 
en la corte y puede ser sujeto a examen y repregunta. La jurisprudencia ha ideado las siguientes excepciones que discutiremos someramente.

\section{Testimonio dado en una acción previa.}

Algunas veces es necesario usar el testimonio de un testigo que ha sido dado en una causa anterior, pero este testigo ya no está disponible. La reproducción de ese testimonio puede hacerse por un testigo que oyó la declaración original. En estos casos, las cortes admitirón el testimonio del testigo que oyó el primer testimonio sólo si las dos acciones (litigios) tienen identidad substancial entre las partes. La admisibilidad se justifica $\alpha$ base de la presunción que el testigo en cuestión ha sido examinado y repreguntado ampliamente por la parte que es idéntica con la parte en el segundo pleito.

\section{Acdmisiones.}

Admisiones son palabras o escritos de una parte que se usan contra esa misma parte. Por ejemplo, si en un accidente automovilístico un testigo oye a una de las partes decir "mis frenos me fallaron" o "yo iba muy rápido y no pude parar", tales palabras son en realidad una admisión de culpabilidad, y su admisibilidad se basa en que una persona normalmente no admite nada perjudicial a ella misma al menos que sea cierto. Una confesión de un delito es también un aspecto de la admisión, aunque en lo referente $\alpha$ confesiones el Juez tiene que determinar primero si la confesión fué voluntaria; de lo contrario violaría el privilegio de una persona de no dar testimonio contra sí misma, lo cual está garantizado por la Constitución Nacional y las constituciones estatales.

\section{Declaraciones contra Intereses.}

Estas declaraciones no deben confundirse con las admisiones. Las admisiones son de naturaleza general, mientras que una declaración contra intereses tiene que ser contra los intereses pecuniarios o económicos del declarante. Por ejemplo en un caso reciente una muchacha menor de edad tuvo un accidente automovilístico. Su padre el día siguiente transfirió toda su propiedad a su esposa. La corte consideró esta acción como una declaración contra los intereses, ya que era una admisión tácita de culpabilidad.

\section{Declaraciones de Muerte.}

Estas son declaraciones hechas por una persona antes de morir, $Y$ que un testigo ha oído. Tales declaraciones serán admisibles si reunen los siguientes requisitos: 1) la persona declarante debe ser la víctima de un homicidio; estas declaraciones se limitan a casos de homicidio; 2) la persona declarante debe tener la creencia que su muerte es inminente. Esta última condición es de suma importancia, pues se basa en la convicción que si una persona sinceramente cree que va $\alpha$ morir, no querró mentir antes de presentarse a su Creador, lo que garantiza la veracidad de la declaración.

13. Constitución Nacional Enmienda V. 


\section{Partidas de Negocios.}

Esta excepción se refiere $\alpha$ ingresos que una persona hace en sus libros de negocios. Pero la excepción se interpreta estrictamente, pues los: ingresos deben hacerse en el curso regular de los negocios, y debe existir una obligación de anotar los ingresos. El Derecho presume que bajo estas condiciones los ingresos se harán correctamente. Es claro que si una persona presta dinero a sus amigos y apunta los préstamos en un libro, tales partidas no pueden admitirse bajo esta excepción, porque el prestamista no está en el negocio de préstamo y sólo hizo préstamos a base de amistad.

\section{Declaraciones Oficiales Escritas.}

Como la excepción anterior, las declaraciones oficiales escritas deben ser hechas en cumplimiento de un deber oficial público, y las declaraciones mismas deben referirse a cuestiones oficiales. Además, el funcionario que las hace debe tener conocimiento personal de lo que ha escrito, de modo que sus declaraciones no pueden basarse en declaraciones de hearsay, pues tendríamos entonces casos de hearscry doble o múltiple.

\section{Res Gestae.}

Por res gesiae se entiende palabras o frases que acompañan ciertos actos o condiciones. Estas declaraciones son generalmente espontáneas $y$ excitadas, $y$ deben hacerse al mismo tiempo que el acto sucedió o inmediatamente antes de que haya sucedido. Por ejemplo, si una mujer dice a su madre antes de salir de la casa "yo voy a ver a fulano de tal", Y al día siguiente a esta mujer se la encuentra muerta víctima de un homicidio, su madre es competente para dar testimonio sobre la declaración que oyó. También si una persona dice, refiriéndose a un automóvil que viene muy ligero, "ese automóvil nos a va atropellar", y en efecto la atropella; si un testigo oyó esta declaración, el último puede dar testimonio sobre lo que oyó.

\section{Declaraciones de Genealogía.}

Esta es una de las excepciones más antiguas y se refiere a declaraciones relativas a la genealogía de una familia o de una persona. La admisibilidad de esta excepción puede surgir en un caso donde es necesario probar que tal o cual persona perteneció a una familia determinada hace ya algún tiempo. Antes de admitir la declaración de esta persona sobre tal o cual acontecimiento familiar, es preciso probar que esta persona exa en realidad un miembro de la familla. La prueba de parentezco debe provenir de fuentes distintas de la declaración en cuestión. Una vez que se ha probado que la persona era miembro de la familia, su declaración sobre la genealogía de la familia se admitirá sin dificultad ninguna.

\section{Reputación Antigua.}

Aquí nos referimos a la reputación o fama de una localidad o cuestiones de interés público. De esta manera, acontecimientos de mucha anti- 
güedad en una comunidad se admitirán a base del testimonio de miembros de esa comunidad. Esta excepción ha jugado un papel importante en la determinación de los límites de una propiedad. Si la comunidad consideró ciertos límites como verdaderos, esta reputación se puede ofrecer por testimonio de personas que pertenecen a la comunidad y que, naturalmente, tienen conocimiento personal de esa reputación o tradición.

\section{Tratados y Listas Comerciales.}

Tratados técnicos y científicos por lo general no son admisibles. Alabama es quizá el único Estado de la Unión que los admite libremente. Otros Estados admiten tratados para impugnar el peritaje de un testigo experto, pero sólo cuando este testigo reconoce el tratado como una obra de autoridad y se basa en ella para sostener sus opiniones. En cuanto a listas comerciales, deben reunir los siguientes requisitos: 1) ser publicadas para el uso de personas ocupadas en ese negocio; 2) las listas deben ser usadas y confiadas por esas personas; $y$ 3) las listas se compilan a base de ventas o cualquier otra condición del mercado. De esta manera se garantiza que las listas no sean arbitrarias y que sean dignas de confianza.

\section{Escritos Antiguos.}

Una declaración en un escrito antiguo será admitida si tiene al menos 50 años de antigüiedad, proviene de un lugar donde está propiamente en custodia y estó libre de sospecha de fraude. Esta excepción por lo general surge en relación con testamentos, certificados de propiedad $y$ otros documentos que prueban ciertos actos jurídicos.

Estas, pues, son las líneas generales de la prueba en el Derecho Anglo-Americano. Existen otras instituciones jurídicas que se estudian en esta rama del Derecho, pero que estrictamente no son pruebas. Incluídas en esta categoría podemos mencionar la presunción, que las cortes no consideran como prueba sino más bien como una regla de derecho que deteimina la carga de la prueba (14). Esta es la regla mayoritaria en los Estados Unidos. La carga de la prueba es más bien una regla de procedimiento que ayuda al Juez a determinar si el caso debe pasar al jurado para su decisión. Si una de las partes no ha descargado la carga de la prueba que le corresponde, a petición de la otra parte el Juez puede disponer del caso dando un "directed verdict". Pero estos son casos excepcionales, y el Juez al acceder a esta petición tiene que considerar el efecto que tendró en el derecho de las partes $\alpha$ un juicio por jurado. Como conclusión, debe añadirse que estas son las reglas principales que ayudan al Juez y al jurado a determinar la verdad de los hechos y así a administrar la justicia de acuerdo con los derechos sagrados que la Constitución garantiza a todo litigante.

14. Jefferson Standard Iife Insurance Co. 7 . Clemer, 79 F. 2d 724, 103 A.L.R. 171 (C.C.A., Va., 1935). 